\title{
Molecular Docking Study on Some Isonicotinoyl Hydrazide Derivatives as Potential Inhibitors of COVID-
}

\author{
Nasser Mohammed Hosny ${ }^{1 *(D)}$, Yousery Sherif ${ }^{2}$ \\ 1 Chemistry Department, Faculty of Science, Port Said University, Port Said, POB 42522, Egypt \\ 2 Clinical Pharmacology Department, Faculty of Medicine, Mansoura University, Mansoura, Egypt \\ * Correspondence: Nasserh56@yahoo.com;
}

Scopus Author ID 55893672800

Received: 13.05.2020; Revised: 10.06.2020; Accepted: 12.06.2020; Published: 16.06.2020

\begin{abstract}
Coronavirus (COVID-19) is more than a health disaster;it is the greatest challenge that the world confrontsnowadays. There is a race to slow the spread of this disease. Searching for an antiviral agent to stop COVID-19 is an essential demand since there is no approved drug for COVID-19 till now. Molecular docking is a powerful tool in predicting new drugs. In this study, Favpiravir (Avigan), Hydroxychloroquine, and a series of biologically active compounds derived from iso-nicotinoyl hydrazide have been chosen for molecular docking study. Molecular docking was carried out by theMolegro virtual docker program on proteaseenzyme of COVID-19.The results showed that all the studied molecules are located in the active sites of protease after molecular docking. The tested nicotinoyl hydrazide derivatives showed a higher ranking docking score than Favpiravir (Avigan). According to the docking score ranking rearrangement, Hydroxychloroquine comes the third, and Favpiravir comes the last among the tested compounds. N(2-iso-nicotinoyl hydrazinecarbonthioyl)benzamide(2) and the enol form of (E)-N-(1-phenylethylidene)-nicotinohydrazide(7) have shown the highest docking score (123.23 and $-123.12 \mathrm{kcal} / \mathrm{mol}$ respectively) among the tested compounds. Ligands (2) and (7) are expected to be potential inhibitors of the main protease enzyme of coronavirus.
\end{abstract}

Keywords: COVID-19; Isonicotinoylhydrazide; Molecular docking; Coronavirus.

(C) 2020 by the authors. This article is an open-access article distributed under the terms and conditions of the Creative Commons Attribution (CC BY) license (https://creativecommons.org/licenses/by/4.0/).

\section{Introduction}

Nobody in the world knows when life will turn to be normal because of COVID-19 or the coronavirus. It is not only a health crisis,but also, it is the cause of difficult economic, social, and political problems all over the world. There are many different kinds of Coronaviruses thatcan cause disease. The newly identified type is called COVID-19. The virus responsible for COVID-19 is similar to that one that caused the 2003 SARS: The two are types of coronaviruses, but COVID-19 seems to spread faster than the 2003 SARS and also may cause less severe illness [1].

Molecular docking is an important tool in drug-drug design [2,3]. To design an antiviral drug, one must look for targets in the virus;Coronavirus main proteases are considered attractive targets.

Coronaviruses contain a genome composed of large RNA, which acts as a messenger RNA and directs the synthesis of polyproteins in the host cell. Polyproteins is essential for a 
replication/transcription complex that generates new virions. The main proteases have a vital role in slashing the polyproteins into functional fragments. The main protease (PDB entry 6Lu7) is a dimer that has two typical active subunits. It has similarity with trypsin, but cysteine and histidine amino acids are responsible for the cutting reaction. The protein structure is a peptide-like inhibitor restricted in the active site [4-6].

Isoniazid (isonicotinic acid hydrazide), which is abbreviated to (INH) is a well-known hydrazide that has various important biological applications. It is a well-known drug for the treatment of TB tuberculosis. Besides that, it exhibits antitumoral, antimicrobial and antiinflammatory activities [7]. Isonicotinic acid hydrazide exhibited very strong in vivo inhibitory action towards $M$. tuberculosis H37Rv. Many derivatives of INH exhibited high inhibitory activity against various strains of $M$. tuberculosis were studied [8,9]. Pyridine derivatives of Isoniazid exhibited strong cytotoxicity and good activities against both Gram-positive and Gram-negative bacteria and mycobacteria $[10,11]$.

In this work a molecular docking study to inhibit coronavirus was carried out on a series of very strong cytotoxic isonicotinic acid hydrazide derivatives: N-benzyl-2-iso nicotinoyl hydrazine-1-carbothioamide (1) [12], N-(2-isonicotinoylhydrazine-carbonothioyl) benzamide (2) [13], 2-isonicotinoyl-N-phenylhydrazine-1-carbothioamide (3) [14], 2-isonicotinoyl-Nphenylhydrazine-1-carboxamide (4) [15]. 4-Acetylpyridine nicotinoylhydrazone(5) [16], (E)$N^{-}$-(1-Phenylethylidene)nicotinohydrazide(6) [17]. This study may assist in finding a new drug for the treatment of COVID-19.

\section{Materials and Methods}

\subsection{Methodology.}

The crystal structure of the molecular target, protease enzyme (COVID-19 3clpro /M pro (PDB ID: 6LU7), was taken from RCSB protein data bank (https://www.rcsb.org/) [18].

For the molecular docking, two drugs (Favpiravir and Hydroxychloroquine) andisonicotonyl derivatives have been included in the current study. The structures of the studied ligands were drawn through Chem office 2015 freeware, and the 3D chemical structures were optimized for energy minimization using (AMBER) force field and saved in.mol format subsequently converted into .pdb format. By hyperchem program 8.1 [19]. To prepare the ligands for the molecular docking study, the water molecules and native ligands attached to the target and other heteroatoms that hindered the simulation were removed. Then the docking processes were carried out on the Molegro virtual docker 2013 window execution file [20].

\section{Results and Discussion}

Molecular docking score, protein ligands interactions, and the hydrogen bond formed with the target protease of COVID-19 are presented in Table 1. The reason forthe choice of these organic ligands is attributed to its very strong in vitro cytotoxic activities against various cancer cell lines. The best poses of the ligands and protease complexes are presented in Figs 17.

The protease enzyme is an essential enzyme in the reproduction of the virus, so inhibiting this enzyme is themain target for designing antiviral drugs. The interactions of the ligands with theseenzymes together with the possible hydrogen bonds and electrostatic interactions are discussed. 


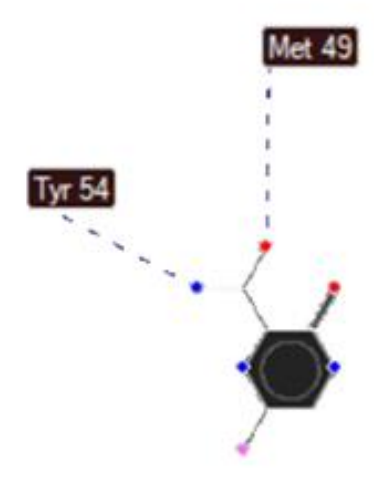

Favpiravir

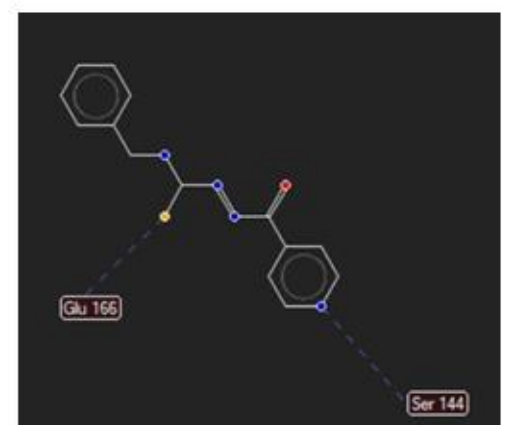

(1)

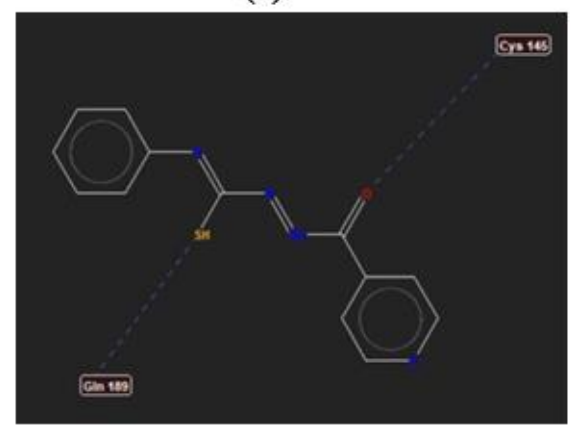

(3)

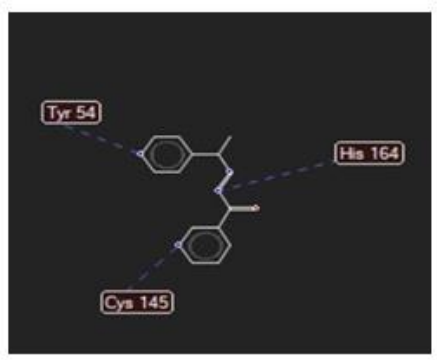

(5)

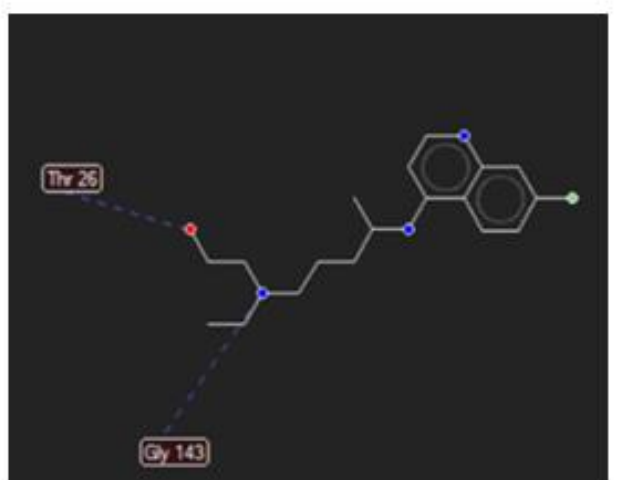

Hydroxychloroquine

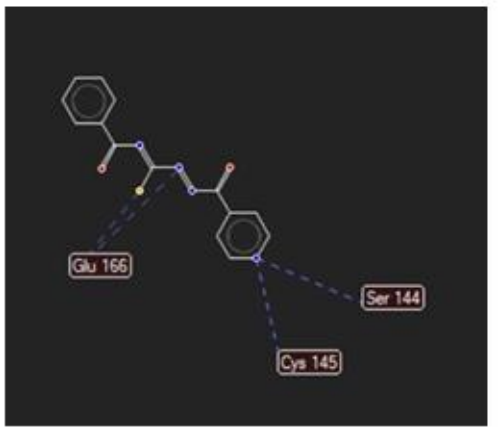

(2)

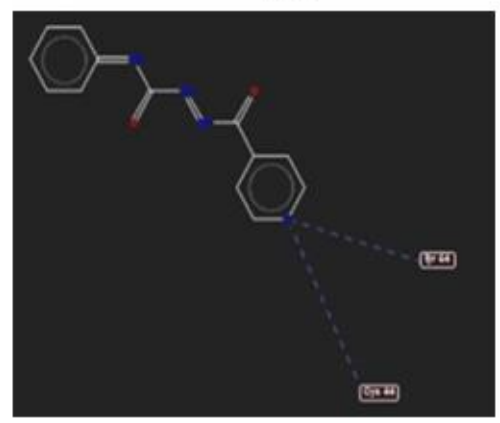

(4)

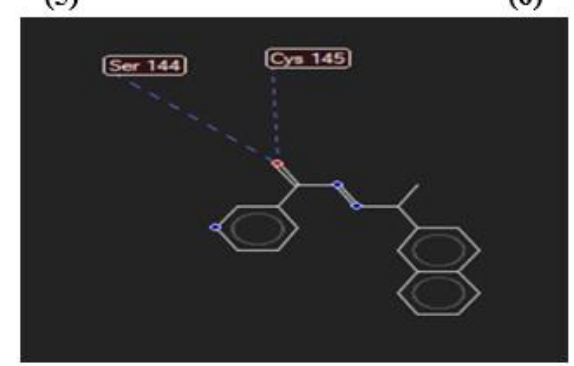

(7)

Figure 1. 2D digram hydrogen bond between the ligands and (6LU7). 
The inhibitory activity of Favipiravir (Avigan) was attributed to its attachment to protease enzyme by hydrogen bonds with Tyr $54(2.67 \AA$ and energy $-3.60 \mathrm{kcal} / \mathrm{mol})$ and His $163(2.91 \AA$ and energy of $-3.56 \mathrm{k} \mathrm{cal} / \mathrm{mol})$. Besides that, there are protein-ligand interactions.

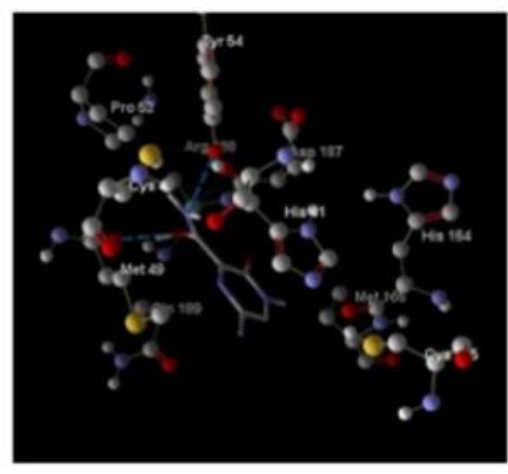

(A)

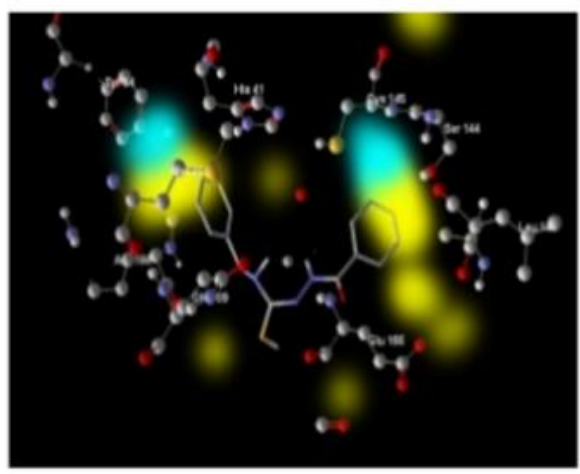

(B)

Figure 2. (A) 3D diagram interaction between Ligand (1) and (6LU7). (B) H-Donor (yellow) H-acceptor (Blue) of Ligand (1).

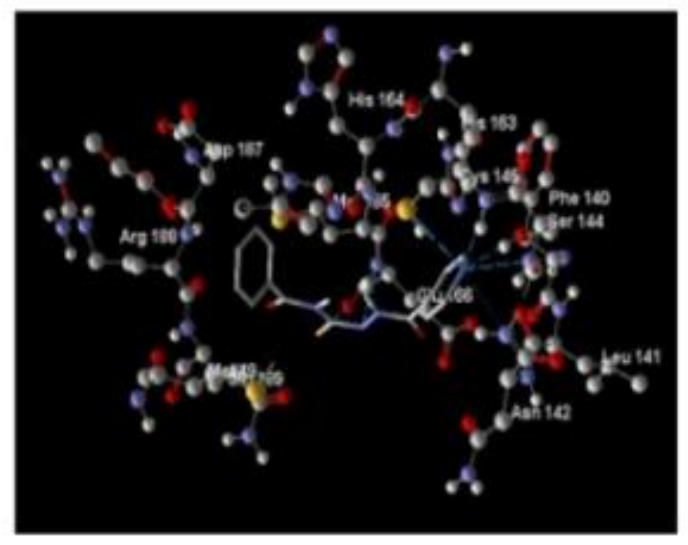

(A)

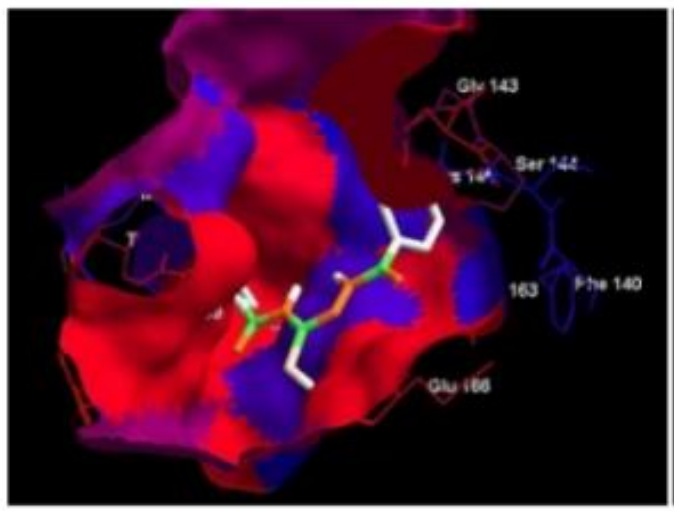

(C)

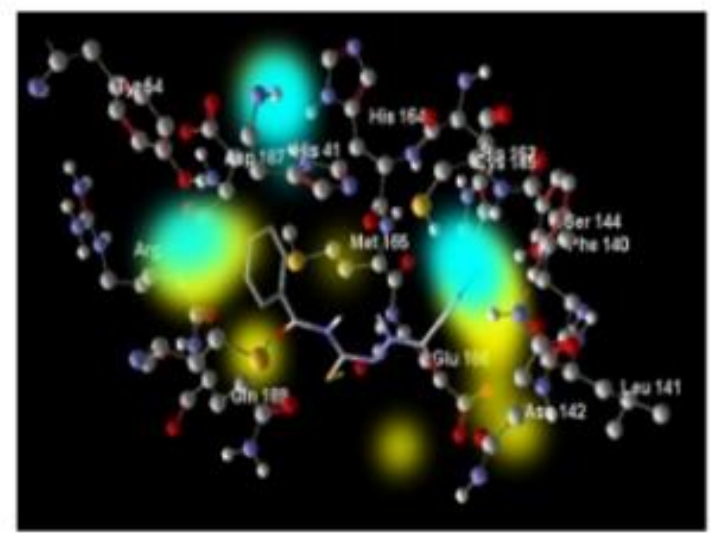

(B)

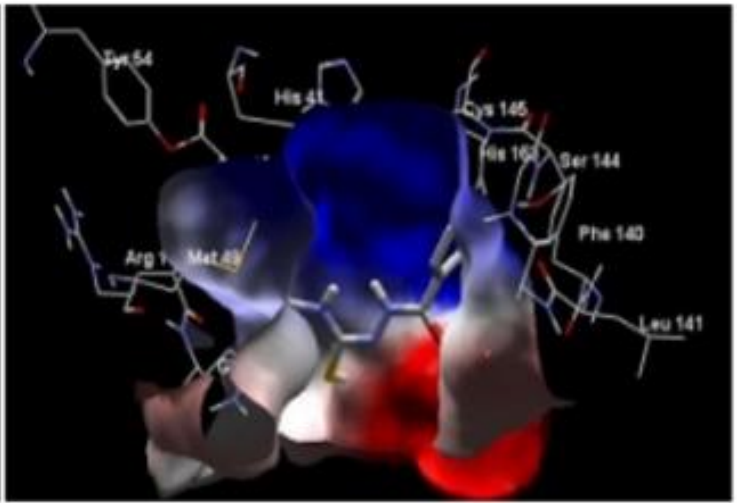

(D)

Figure 3. (A) 3D diagram interaction between Ligand (1) and (6LU7). (B) H-Donor (yellow) H-acceptor (Blue), (C) Hydrophobicity red colorhydrophilic residue; Blue color hydrophobicresidue, ( D) electrostatic interaction Blue Positive charge RedNegative charge of Ligand (2)

Hydroxychloroquine can form two hydrogen bonds, One with Thr 26 with a distance of about $3.10 \AA$ and energy $-3.19 \mathrm{k} \mathrm{cal} / \mathrm{mol}$, and the second hydrogen bondis formed between 
the amino acid residue Gly 143 (distance about $2.78 \AA$ and energy of $-2.59 \mathrm{kcal} / \mathrm{mol}$ ). Noticeably, there arevery strong interactions between Hydroxychloroquine and the protein.

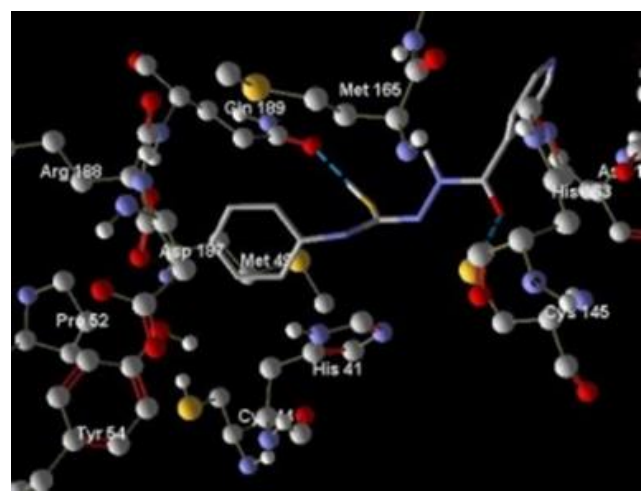

Figure 4. 3D diagram interaction between Ligand (3) and (6LU7).

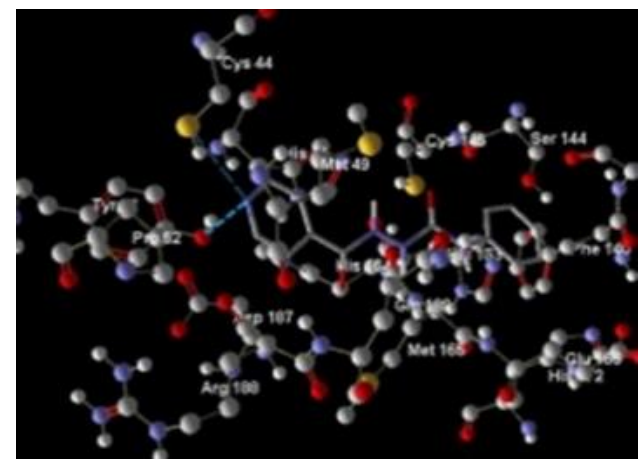

Figure 5. 3D diagram interaction between Ligand (4) and (6LU7).

In case of Ligand (1), two hydrogen bonds interaction are possible between $\mathrm{S}$ atom of the thiol group with Glu 166 (distance about $2.97 \AA$ and energy of $-2.50 \mathrm{kcal} / \mathrm{mol}$ ) and pyridyl $\mathrm{N}$ with Ser 144 (distance about $3.02 \AA$ and energy of $-2.5 \mathrm{~K} \mathrm{cal} / \mathrm{mol}$ ).

Ligand (2) is the most promising one among the tested compounds with the highestranking score $(-123.23 \mathrm{Kcal} / \mathrm{mol})$ as it binds to the protein through three hydrogen bonds. It forms two hydrogen bonds with the amino acid Glu 166 through thioamide $\mathrm{S}$ and $\mathrm{N}$, at the same time, it makes two hydrogen bonds via pyridyl N with both Ser144 (distance about 3.13 $\AA$ and energy of $-2.34 \mathrm{kcal} / \mathrm{mol}$ ) and Cys145 (distance about $2.92 \AA$ and energy of -1.15 $\mathrm{kcal} / \mathrm{mol}$ ). Besides that, there are hydrophobicity and electrostatic interactions between (2) and the protein.

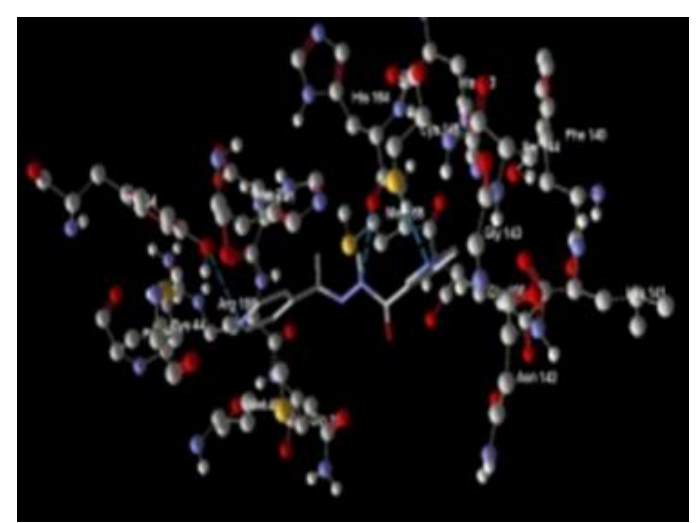

Figure 6. 3D diagram interaction between Ligand (5) and (6LU7).

Ligand (3) binds to the protein through a hydrogen bond of thiol S with Gln 189 (distance about $2.99 \mathrm{~A}^{0}$ and energy of $-2.5 \mathrm{kcal} / \mathrm{mol}$ ) and a second hydrogen bond between 
carbonyl O with Cys145( distance about $2.65 \AA$ and energy of $-2.5 \mathrm{kcal} / \mathrm{mol}$ ). There are hydrophobic and electrostatic interactions between (3) and the protein.

Ligand (4) binds to the protein through electrostatic and hydrophobic interactions together with two hydrogen bonds between pyridyl N with Tyr 54 (distance about $2.93 \AA$ and energy of $-2.5 \mathrm{kcal} / \mathrm{mol}$ ) and Cys 44 (distance about $3.34 \mathrm{~A}^{0}$ and energy of $-1.30 \mathrm{kcal} / \mathrm{mol}$ ).

Ligand (5), thesecompounds forms two hydrogen bonds between pyridyl Ns with Cys 145 (distance about $3.11 \AA$ and energy of $-2.43 \mathrm{kcal} / \mathrm{mol}$ ) and with Tyr 54 (distance about 3.28 $\AA$ and energy of- $1.58 \mathrm{kcal} / \mathrm{mol}$ ). The carbonyl group forms a third hydrogen bond with the amino acid residue His 164 (distance about $3.28 \AA$ and energy of- $1.58 \mathrm{kcal} / \mathrm{mol}$ ). There is relatively weak interactions between (4) and the protein.

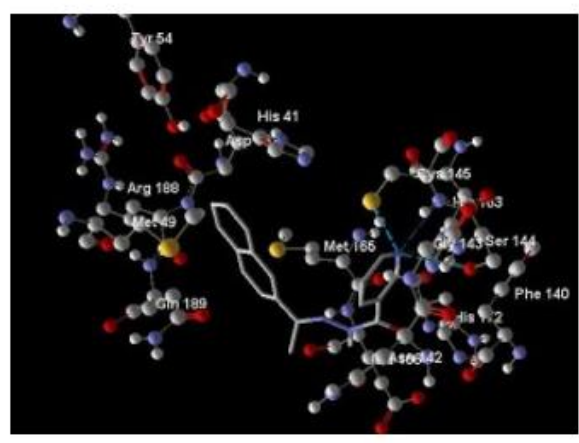

(A)

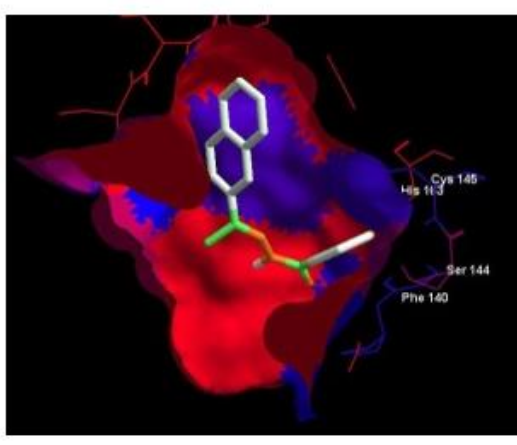

(B)

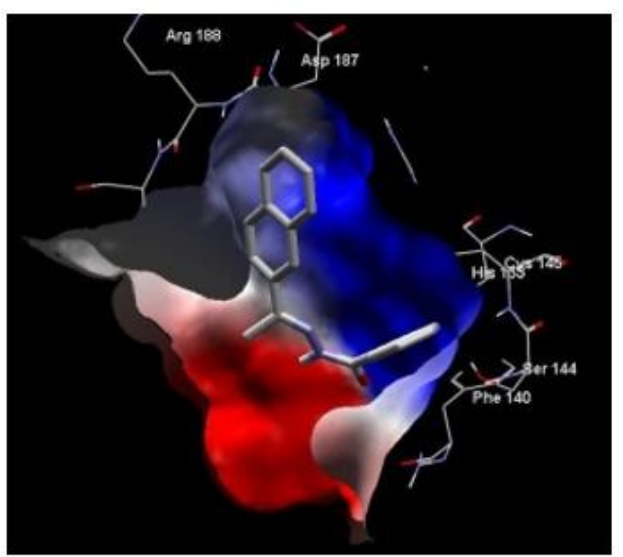

(C)

Figure 7. (A) 3D diagram interaction between Ligand (6) and (6LU7). (B) Hydrophobicity red color hydrophilic residue; Blue color hydrophobicresidue, ( C) electrostatic interaction blue positive charge red negative charge of Ligand (6).

Ligand (6) represents the keto form of $(E)-N^{-}$-(1-Phenylethylidene) nicotinohydrazide. It has high ranking docking score; this compound binds through the pyridyl $\mathrm{N}$ with both Ser 144 ( distance about $3.52 \AA$ and energy of $-0.16 \mathrm{kcal} / \mathrm{mol}$ ) and acid Cys 145 ( distance about $2.74 \AA$ and energy of $-2.5 \mathrm{k} \mathrm{cal} / \mathrm{mol}$ ). There isa very strong hydrophobic and electrostatic interaction (Figs $7 \mathrm{~B}$ and C). Ligand (7) represents the enol form of (6), it has the highest docking ranking score together with (2). It binds with the proteinvia two hydrogen bonds between the carbonyl oxygen and both Ser 144 (3.18 $\AA$ and energy of $-0.90 \mathrm{kcal} / \mathrm{mol})$ and Cys 145 (distance about $2.87 \mathrm{~A}^{0}$ and energy of $-76 \mathrm{k} \mathrm{cal} / \mathrm{mol}$ ). It is clear that the docking score of the keto form (6) of the ligand $(E)-N^{-}$- (1-Phenylethylidene)nicotinohydrazide and the enol form (7)are approximately the same. There are very strong hydrophobic and electrostatic interactions in these two compounds (Figs $8 \mathrm{~B}$ and C). Noticeably, the very strong electrostatic 
interactions of Ligands (6) and (7) come from the high pi-systems resulted from the presence of three aromatic rings available to interact through pi-pi stacking or pi-cation interactions. According to the molecular docking ranking score the Ligands are arranged in the following order: Ligand (2)> Ligand (7)> Ligand (6)> Hydroxychloroquine > Ligand (1)> Ligand (3)> Ligand (4)> Ligand (5)>Favpiravir (Avigan).

Table 1. Molecular docking score, protein-ligand interactions and hydrogen bonds energy (Kcal/mol).

\begin{tabular}{|c|c|c|c|c|}
\hline $\begin{array}{r}\text { Ligand } \\
\text { No. }\end{array}$ & Name of the ligand & $\begin{array}{l}\text { Docking } \\
\text { Score }\end{array}$ & $\begin{array}{l}\text { Protein-Ligandd } \\
\text { Interactions }\end{array}$ & $\begin{array}{l}\text { H-bond } \\
\text { Energy }\end{array}$ \\
\hline Drug 1 & Favpiravir (Avigan) & -65.45 & -75.47 & -2.99 \\
\hline Drug 2 & Hydroxychloroquine & -4.93 & -131.60 & -116.17 \\
\hline (1) & $\begin{array}{l}\text { N-benzyl-2-iso nicotinoyl hydrazine-1- } \\
\text { carbothioamide }\end{array}$ & -3.73 & -126.82 & -113.81 \\
\hline (2) & $\begin{array}{l}\mathrm{N} \text {-(2-isonicotinoylhydrazine- } \\
\text { carbonothioyl) benzamide }\end{array}$ & -11.53 & -128.13 & -123.23 \\
\hline (3) & $\begin{array}{l}\text { 2-isonicotinoyl-N-phenylhydrazine-1- } \\
\text { carbothioamide }\end{array}$ & -5.00 & -117.78 & -112.91 \\
\hline (4) & $\begin{array}{l}\text { 2-isonicotinoyl-N-phenylhydrazine-1- } \\
\text { carboxamide }\end{array}$ & -3.80 & -124.34 & -108.82 \\
\hline (5) & 4-Acetylpyridine nicotinoylhydrazone & -5.62 & -111.90 & -105.11 \\
\hline (6) & $\begin{array}{l}\text { Keto }\left((E)-N^{-}-(1-p h e n y l e t h y l i d e n e)\right. \\
\text { nicotinohydrazide }\end{array}$ & -5.32 & -136.82 & -122.37 \\
\hline (7) & $\begin{array}{l}\text { Enol }\left((E)-N^{-}-(1-P h e n y l \text { ethylidene })\right. \\
\text { nicotinohydrazide }\end{array}$ & -4.16 & -136.41 & -123.12 \\
\hline
\end{tabular}

\section{Conclusions}

This work can help in saving time in looking for new drugs for the treatment of COVID19 or similar viral infections. A series of compounds of isonicotinoyl hydrazide derivatives have been studied by molecular docking compared with two well-known drugs (Favpiravir, Hydroxychloroquine), which are used in treatment of COVID-19. The suggested compounds showed promising results.

\section{Funding}

This research received no external funding.

\section{Acknowledgments}

This research has no acknowledgment.

\section{Conflicts of Interest}

The authors declare no conflict of interest.

\section{References}

1. Lee, P.I.; Hsueh, P.R. Emerging threats from zoonotic coronaviruses-from SARS and MERS to 2019-nCoV. J Microbiol Immunol Infect 2020, 20, 30011-30016,https://doi.org/10.1016/j.jmii.2020.02.001.

2. Arba, M.; Arfan, Nuralifah, A.A.;Haerunnisah, W.O.; Kadidae, L.In silico exploration for aldose reductase (AR) inhibitors.Letters in Applied NanoBioSciene2020,9,956-960.

3. Radwan, A.; Khalid, M.; Amer, H.; Alotaibi, M. Anticancer and molecular docking studies of some new pyrazole-1-carbothioamide nucleosides.Biointerface Research in Applied Chemistry2019, 9, 46404648,https:///doi.org/10.33263/BRIAC96.642648.

4. Lu, R.; Zhao, X.; Li, J.; Niu, P.; Yang, B.; Wu, H.; Wang, W.; Song, H.; Huang, B.; Zhu, N.; Bi, Y.; Ma, X.; Zhan, F.; Wang, L.; Hu, T.; Zhou, H.; Hu, Z.; Zhou, W.; Zhao, L.; Chen, J.; Meng, Y.; Wang, J.; Lin, Y.; Yuan, J.; Xie, Z.; Ma, J.; Liu, W.J.; Wang, D.; Xu, W.; Holmes, E.C.; Gao, G.F.; Wu, G.; Chen, W.; Shi, W.; Tan, W. Genomic characterisation and epidemiology of 2019 novel coronavirus: implications for virus 
origins and receptor binding. The Lancet 2020, 395, 565-574, https://doi.org/10.1016/S01406736(20)30251-8.

5. Cui, J.; Li, F.; Shi, Z.L. Origin and evolution of pathogenic coronaviruses. Nat. Rev. Microbiol. 2019, 17, 181-192,https://doi.org/10.1038/s41579-018-0118-9.

6. John, S.E.; Tomar, S.; Stauffer, S.R.; Mesecar, A.D. Targeting zoonotic viruses: Structure-based inhibition of the 3C-like protease from bat coronavirus HKU4-The likely reservoir host to the human coronavirus that causes Middle East Respiratory Syndrome (MERS). Bioorg.Med.Chem. 2015, 23, 60366048,https://doi.org/10.1016/j.bmc.2015.06.039.

7. Rao, D.P. A review on versatile applications of novel Schiff bases and their metal complexes..Biointerface Research in Applied Chemistry2019, 8, 675-681.

8. Kaymakçığlu, K.B.; Rollas, S. Synthesis, characterization and evaluation of antituberculosis activity of some hydrazones. Farmaco2002, 57, 595-599,https://doi.org/10.1016/S0014-827X(02)01255-7.

9. Bavin, E.M.; Drain, D.J.; Seiler, M.; Seymour, D.E. Some further studies on tuberculostatic compounds. $J$. Pharm. Pharmacol. 1954, 4, 844-855, https://doi.org/10.1111/j.2042-7158.1952.tb13218.x.

10. Buu-Hoi, P.H.; Xuong, D.; Nam, H.; Binon, F.; Royer, R. Tuberculostatic hydrazides and their derivatives .J. Chem. Soc. 1953, 1358-1364, https://doi.org/10.1039/JR9530001358.

11. Cocco, M.T.; Congiu, C.; Onnis, V.; Pusceddo, M.C.; Schivo, M.L.; De Logu, A. Synthesis and antimycobacterial activity of some isonicotinoylhydrazones. Eur. J. Med. Chem. 1999, 34, 10711076,https://doi.org/10.1016/S0223-5234(99)00124-5.

12. Abdel-Rhman, M.H.; Hussien, M.A., Mahmoud, H.M.; Hosny, N.M. Synthesis, characterization, molecular docking and cytotoxicity studies on N-benzyl-2-iso nicotinoyl hydrazine-1-carbothioamide and its metal complexes.J Mol Struct2019, 1196, 417-428,https://doi.org/10.1016/j.molstruc.2019.06.092.

13. Hosny, N.M.; Mahmoud, H.M.; AbdelRhman, M.H. Spectral, optical, andcytotoxicity studies on N-(2isonicotinoylhydrazine-carbonothioyl) benzamide and its metal complexes.Heteroatom Chemistry 2018 e21415, https://doi.org/10.1002/hc.21415.

14. Hosny, N.M.; Hassan, N.Y.; Mahmoud, H.M.; AbdelRhman, M.H. Synthesis,characterization and cytotoxicity of new 2-isonicotinoyl-N-phenylhydrazine-1-carbothioamide and its metal complexes.Applied Organometallic Chemistry2019,33, e4998,https://doi.org/10.1002/aoc.4998.

15. Hosny, N.M.; Hassan, N.Y.; Mahmoud, H.M.; Abdel-Rhman, M.H. Spectral, optical and cytotoxicity studies on 2-isonicotinoyl-N-phenylhydrazine-1-carboxamide $\left(\mathrm{H}_{3} \mathrm{~L}\right)$ and some of its metal complexes.J Mol Struct2018, 1156, 602-611,https://doi.org/10.1016/j.molstruc.2017.11.114.

16. Hosny, N.M.; Shallaby, A.M. Spectroscopic Characterization of Some Metal Complexes Derivedfrom 4Acetylpyridine Nicotinoylhydrazone, Transition Met. Chem.2007,32, 10851090,https://doi.org/10.1007/s11243-007-0288-1.

17. Hosny,N.M. Synthesis and spectroscopic studies of (E)-N_-(1-phenylethylidene)-nicotinohydrazide (PNH) and some of its metal complexes. J. Mol. Struct. 2009,923, 98102,https://doi.org/10.1016/j.molstruc.2009.02.008.

18. M pro (PDB ID: 6LU7), was retrieved from RCSB protein data bank (https://www.rcsb.org)

19. Molegro virtual docker 6.0, 2013.

20. Hyper chem program version 8.1 developed by Hypercube Inc. 2002. 